\title{
Antimicrobial activity of PVP coated silver nanoparticles synthesized by Lysinibacillus varians
}

\author{
Divya Bhatia $^{2}$ - Ashwani Mittal ${ }^{1} \cdot$ Deepak Kumar Malik $^{2}$
}

Received: 28 June 2016/ Accepted: 29 August 2016/Published online: 7 September 2016

(C) The Author(s) 2016. This article is published with open access at Springerlink.com

\begin{abstract}
Emergence of resistant microbes to conventional antibiotics and increased emphasis on health-care costs has raised the concern for the development of new effective antimicrobial reagents. Silver nanoparticles being an excellent broad-spectrum antibacterial agent could be considered as a suitable alternative for existing antibiotic. This study demonstrates the extra-cellular synthesis of stable silver nanoparticles using supernatant of Lysinibacillus varians. The synthesized silver nanoparticles were characterized by using UV-visible spectrum analysis, X-ray diffraction, Transmission electron microscopy (TEM) and FT-IR analysis. The synthesized silver nanoparticles showed a peak around $420 \mathrm{~nm}$. TEM analysis revealed that the size of silver nanoparticles was in the range of 10-20 nm. Silver nanoparticles carry a charge of $-39.86 \mathrm{mV}$, which confirmed the stability of silver nanoparticles. The biologically synthesized silver nanoparticles showed antimicrobial activity against Grampositive, Gram-negative bacteria and fungi. Therefore, the current study reveals an efficient and eco-friendly synthesis of silver nanoparticles by $L$. varians with potent antimicrobial activity.
\end{abstract}

Deepak Kumar Malik

deepmolbio@ rediffmail.com

1 University College, Kurukshetra University, Kurukshetra, India

2 University Institute of Engineering and Technology, Kurukshetra University, Kurukshetra, India
Keywords Silver nanoparticles · Biosynthesis · Characterization $\cdot$ Antimicrobial

\section{Introduction}

Nanotechnology is an interdisciplinary field which impacts significantly all aspects of human's life (Mohanpuria et al. 2008; Liu et al. 2011). This field deals with the synthesis and applications of nanomaterials in various areas (Duran et al. 2005). Metal nanoparticles exhibit unique properties, which depend on their size, shape, composition, and dielectric surroundings (Hubenthal et al. 2005; Chen and Goodman 2004; Jain et al. 2006). Ag-NPs have numerous applications in the field of diagnostics, textile, catalysis, optics, photography, electronics and food industry (Rai et al. 2009). Silver nanoparticles have been used as antimicrobial agents in surgically implanted catheters, surgical bandages, eye treatment, dental hygiene, bone substitute biomaterials, disinfecting medical devices/home appliances and textile coatings (Bosetti et al. 2002; Cho et al. 2005; Gupta and Silver 1998; Jain and Pradeep 2005; Li et al. 2008). Microbial synthesis of metal nanoparticles can take place either intracellularly or extracellularly (Ahmad et al. 2007; Jain et al. 2011; Kalishwaralal et al. 2010; Pugazhenthiran et al. 2009; Saifuddin et al. 2009). Intracellular synthesis of nanoparticles requires additional steps to release the synthesized nanoparticles (Kalimuthu et al. 2008). At the same time extracellular biosynthesis is cheap and requires simpler downstream processing. This paper reports the extracellular biosynthesis of silver nanoparticles with their potent antimicrobial activity.

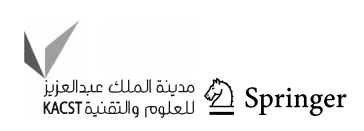




\section{Materials and methods}

\section{Isolation and characterization of bacteria}

All the chemicals used were of analytical grade purchased from Himedia Laboratories Pvt. Ltd., India. The isolation of bacteria for silver nanoparticle synthesis was carried out by serial dilution method from metal contaminated soil (Baker and Shreedharmurthy 2012). The serially diluted soil sample was spreaded over nutrient agar plates. The plates were incubated at $30{ }^{\circ} \mathrm{C}$ for 48 hours. The isolated colonies were further sub-cultured on nutrient agar supplemented with $1 \mathrm{mM}$ silver nitrate $\left(\mathrm{AgNO}_{3}\right)$ for screening of bacterial culture capable to grow in the presence of silver nitrate. The isolated bacterial culture capable to synthesize silver nanoparticles synthesis was characterized by $16 \mathrm{~S}$ rRNA sequencing from the Institute of Microbial Technology, Chandigarh (India).

\section{Extracellular synthesis of silver nanoparticles}

The synthesis of AgNPs was carried out by using extracellular method (Kalishwaralal et al. 2008). The isolated bacterial culture DNP 10 was inoculated in basal salt media (BSM) for 48 hours at $30{ }^{\circ} \mathrm{C}$ under shaking conditions of $220 \mathrm{rpm}$. The composition of BSM was (in $\mathrm{g} / \mathrm{L})\left(\mathrm{NH}_{4}\right)_{2} \mathrm{SO}_{4}, 1.0 ; \mathrm{K}_{2} \mathrm{HPO}_{4}$, $0.1 ; \mathrm{MgSO}_{4}, 0.2 ; \mathrm{FeSO}_{4} \cdot 7 \mathrm{H}_{2} \mathrm{O}, 0.001 ; \mathrm{NaCl}, 1.0 ; \mathrm{Na}_{2} \mathrm{MoO}_{4}$, 0.0033 . After incubation, the broth culture was centrifuged at $8000 \mathrm{rpm}$ for 20 minutes. The supernatant was used for the synthesis of AgNPs. Three Erlenmeyer flasks, first containing supernatant with $2 \mathrm{mM}$ silver nitrate in ratio of $1: 1$ with $0.1 \%$ polyvinyl pyrrolidone (PVP) as a stabilizing agent, second containing only supernatant and third containing only silver nitrate solution were incubated under bright conditions for 30 minutes. The appearance of brown colour was an indicator for the synthesis of AgNPs. The extracellular synthesis of AgNPs was monitored by observing change in the colour of the culture supernatant from transparent to brown.

\section{Characterization of silver nanoparticles}

The silver nanoparticle synthesis was further confirmed by $\mathrm{UV}-\mathrm{V}$ is spectroscopy analysis in the range of 300-900 nm by using a UV-2550 PC UV-Vis spectrometer (Shimadzu, UV Pharma spec 2550 with a resolution of $0.72 \mathrm{~nm}$ ). The deionized water was used as blank for all measurements. The Silver nanoparticles were separated by centrifugation at $10,000 \mathrm{rpm}$ for 40 minutes at $4{ }^{\circ} \mathrm{C}$. The pellet was washed five times with distilled water, air dried and used for further characterization. The purified silver nanoparticles were characterized by X-ray diffraction (XRD), for phase structure and exact material identification. The size and shape of silver nanoparticles was analyzed by TEM using Hitachi (H-7500) with an electron kinetic energy of $120 \mathrm{kV}$ at CIL, Panjab University, Chandigarh. The sizedistribution profile and zeta potential of silver nanoparticles was studied by using dynamic light scattering (DLS) measurements conducted with a Microtrac Nanotrac Wave Particle Size, Zeta Potential analyzer. The FTIR spectrum was studied by using FT-IR spectrophotometer (Horizon $\mathrm{ABB}$ ) between the spectral range of $4000-400 \mathrm{~cm}^{-1}$ at a scan speed of $16 \mathrm{~cm} / \mathrm{s}$.

\section{Analysis of Antimicrobial activity of AgNPs}

The antimicrobial activity of biologically synthesized silver nanoparticles was tested against ten different test pathogens (seven bacteria and three fungi). The test micro-organisms used were Escherichia coli (MTCC No 40), Bacillus subtilis (MTCC No 441), Pseudomonas aeruginosa (MTCC No 424), Pseudomonas fluorescens (MTCC No 1748), Staphylococcus aureus (MTCC No 87), Streptococcus mutans (MTCC No 497), Streptococcus pyogenes (MTCC No 1924), Fusarium graminearum (MTCC No 2089), Candida albicans (MTCC No 3017) and Candida glabrata (MTCC No 3019). The cultures were procured from MTCC, Institute of Microbial Technology, Chandigarh. The antibacterial activity of synthesized AgNPs was checked by agar well diffusion assay with some modification (Perez et al. 1990). The nutrient agar plates were spreaded with $100 \mu \mathrm{L}$ inocu$\operatorname{lum}\left(1.5 \times 10^{8} \mathrm{CFU} / \mathrm{mL}\right)$ of each selected pathogen (in triplicates). Three wells were made with sterile borer into inoculated agar plates. The biologically synthesized silver nanoparticles $(70 \mu \mathrm{L})$ were poured into one well of inoculated plates. In other two wells, equal volume of silver nitrate and culture supernatant was poured. These two wells were considered as control. After incubation at $35^{\circ} \mathrm{C}$ for 24 hours, zone of inhibition was measured and recorded as mean $\pm \mathrm{SD}$ of the triplicate experiment.

\section{Minimum inhibitory concentration (MIC)}

Minimum inhibitory concentration of silver nanoparticles against test pathogens (E. coli, Bacillus subtilis, $P$. aeruginosa, $S$. aureus and $C$. albicans) was determined by agar well diffusion assay method with some modifications (Perez et al. 1990). To examine the minimum inhibitory concentration of silver nanoparticles, different concentrations of silver nanoparticles $(375,187.5,93.75,46.85$, and $23.45 \mu \mathrm{g}$ ) were prepared. Two fold serial dilutions of silver nanoparticles were prepared in deionized water. The nutrient agar plates were inoculated with $100 \mu \mathrm{L}$ of standardized inoculum $\left(1.5 \times 10^{8} \mathrm{CFU} / \mathrm{mL}\right)$ of each selected pathogen (in triplicates) and spreaded with sterile swabs. 
The wells of $8 \mathrm{~mm}$ size were made with sterile borer into agar plates containing the inoculums. The lower portion of wells was sealed with a little molten agar medium. Next, the serially diluted silver nanoparticles $(50 \mu \mathrm{L})$ were poured into different wells of inoculated plates. The plates were incubated at $30^{\circ} \mathrm{C}$ for 24 hours. The lowest concentration of silver nanoparticles that inhibits the growth of test pathogens was considered as the minimum inhibitory concentration (MIC).

\section{Results}

The soil sample from metal contaminated site was used for the isolation of bacteria capable to synthesize silver nanoparticles. After screening for their growth over nutrient agar plates containing silver nitrate $\left(\mathrm{AgNO}_{3}\right)$, the bacterial isolate DNP10 was selected for further investigation. Antimicrobial property of silver nitrate is well known since ancient times. It is assumed that bacteria capable to grow in the presence of silver nitrate will have higher chances to produce silver nanoparticles by reducing silver nitrate. However, there is no direct correlation between the growth of isolated bacteria over silver nitrate containing nutrient agar plates and ability to synthesize the silver nanoparticles.

The 16S rDNA sequence data of the DNP10 was subjected to BLAST analysis. The result showed $100 \%$ identity to reported $16 \mathrm{~S}$ rDNA sequence of Lysinibacillus varians. The $16 \mathrm{~S}$ rDNA sequence of the bacterial isolate DNP10 was submitted to NCBI under the accession number KX011876.

The synthesis of silver nanoparticles was observed by the change in colour of culture supernatant in the presence of $\mathrm{AgNO}_{3}$. The flask containing DNP 10 cell free supernatant with silver nitrate $(2 \mathrm{mM})$ and PVP showed colour change from transparent to light yellow within 2 minutes of incubation. The change in colour from light yellow to dark brown was observed after 20 minutes of incubation period as shown in Fig. 1. The two other flasks (control), one contained only supernatant and the other contained only silver nitrate showed no colour change. This suggests that the colour change observed in case of bacterial supernatant with silver nitrate was due to the formation of silver nanoparticles. The biologically synthesized silver nanoparticles were characterized by UV-Visible spectroscopy as shown in Fig. 2. A characteristic sharp peak around $418 \mathrm{~nm}$ wavelength was observed, which confirmed the presence of AgNPs. This is the characteristic wavelength for the synthesis of AgNPs.

The crystal structure of biologically synthesized silver nanoparticles was determined by X-ray diffraction (XRD) analysis. The XRD pattern shows four intense peaks in the whole spectrum of $2 \theta$ values ranging from $20^{\circ}$ to $80^{\circ}$. In

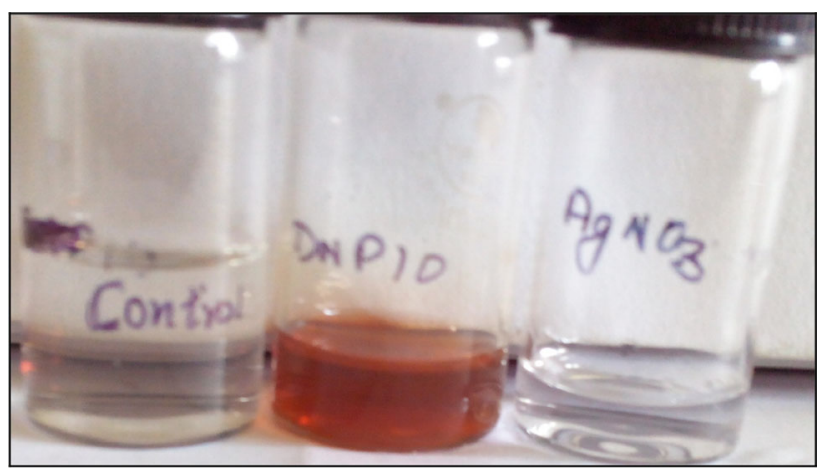

Fig. 1 Extracellular synthesis of silver nanoparticles by bacterial isolate DNP 10

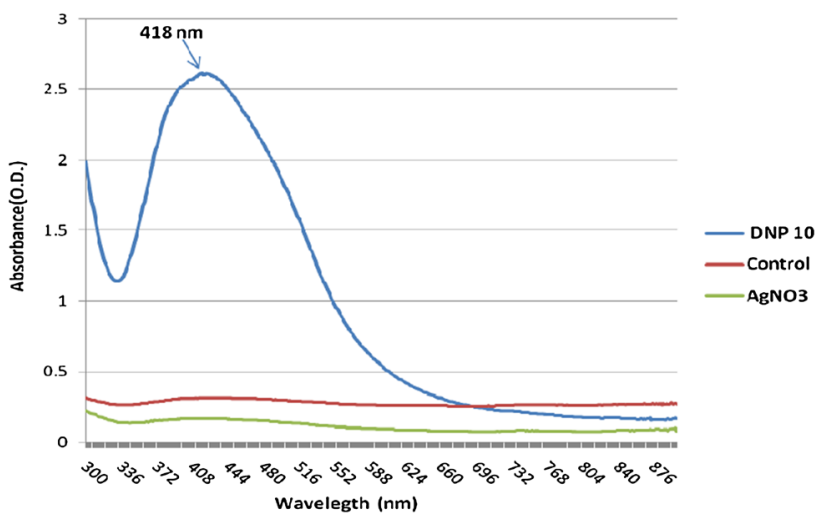

Fig. 2 UV Visible Spectrum analysis of biologically synthesized AgNPs

XRD pattern, three diffractions peaks were observed at $38.07,46.24,54.82$, and 77.110 corresponding to 111,200 , 220, and 311 face centered cubic (fcc) silver planes for metallic silver, respectively as shown in Fig. 3. The size of silver nanoparticles was calculated by using DebyeScherer's equation as shown in Table 1 . The calculated average size of silver nanoparticles was about $27.25 \mathrm{~nm}$. The calculated size was consistent with the nanoparticle size estimated by TEM analysis. The size and shape of the synthesized silver nanoparticles was determined by TEM analysis. In the TEM analysis, silver nanoparticles were spherical in shape with size ranging from 10 to $30 \mathrm{~nm}$ as shown in Fig. 4. The FTIR analysis was carried out to identify possible interactions between silver salts and protein molecules responsible for the reduction of $\mathrm{Ag}^{+}$ions and stabilization of AgNPs. The FTIR spectrum of silver nanoparticles between the wave number $400^{-1}-4000^{-1}$ showed strong peaks at $1651,1528,1288$, and $1057 \mathrm{~cm}^{-1}$ as shown in Fig. 5. The DLS graph of biologically synthesized AgNPs is shown in Fig. 6. The size of AgNPs was around $200-250 \mathrm{~nm}$. The particles carry a charge of $-39.86 \mathrm{mV}$. This confirms that the biologically synthesized silver nanoparticles were stable. 


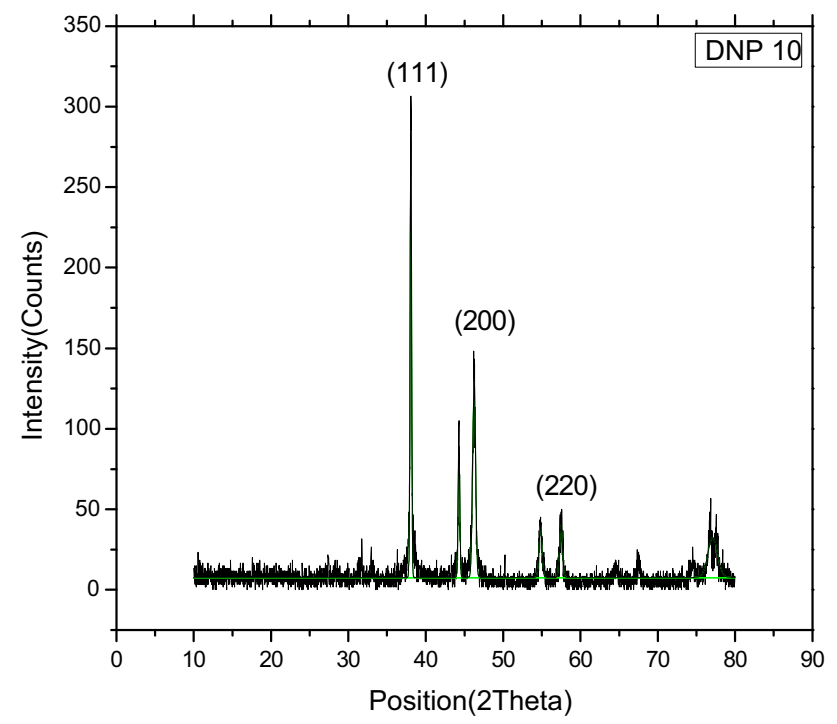

Fig. 3 XRD analysis of biologically synthesized AgNPs

Table 1 Size calculated by Debye Scherrer equation

\begin{tabular}{lll}
\hline Position $(2 \theta)$ & Width & Size $(\mathrm{nm})$ \\
\hline 38.07 & 0.220 & 40.53 \\
46.24 & 0.379 & 24.23 \\
54.829 & 0.380 & 33.79 \\
77.110 & 1.236 & 10.460 \\
\hline
\end{tabular}

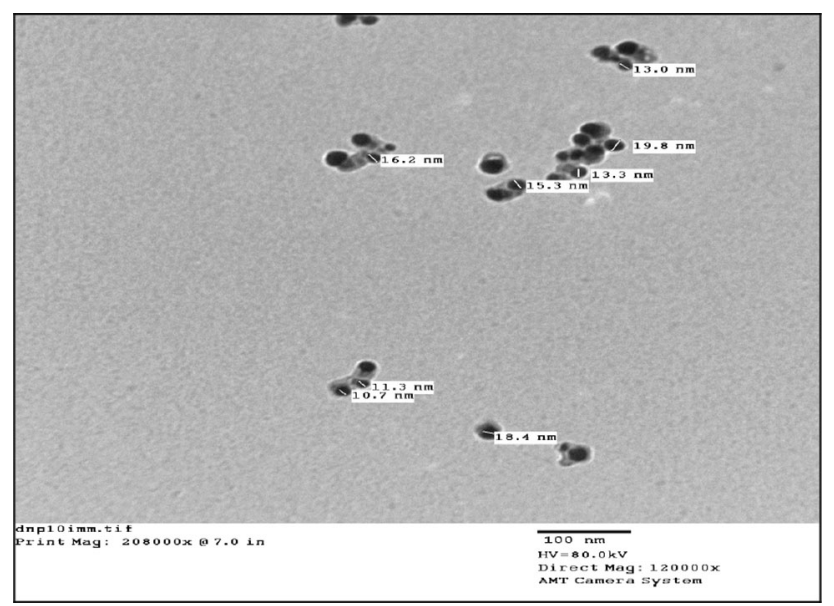

Fig. 4 TEM Analysis of biologically synthesized silver nanoparticles by bacterial isolate DNP 10

The antibacterial activity of biosynthesized silver nanoparticles was checked against Gram-positive bacteria (Bacillus subtilis, S. aureus, S. mutans, S. pyogenes), Gram-negative bacteria (E. coli, P. aeruginosa, P. fluorescens), fungi ( $C$. albicans, $C$. glabrata) and plant pathogen ( $F$. graminearum). The AgNPs synthesized by isolate $L$. varians showed excellent antibacterial activity

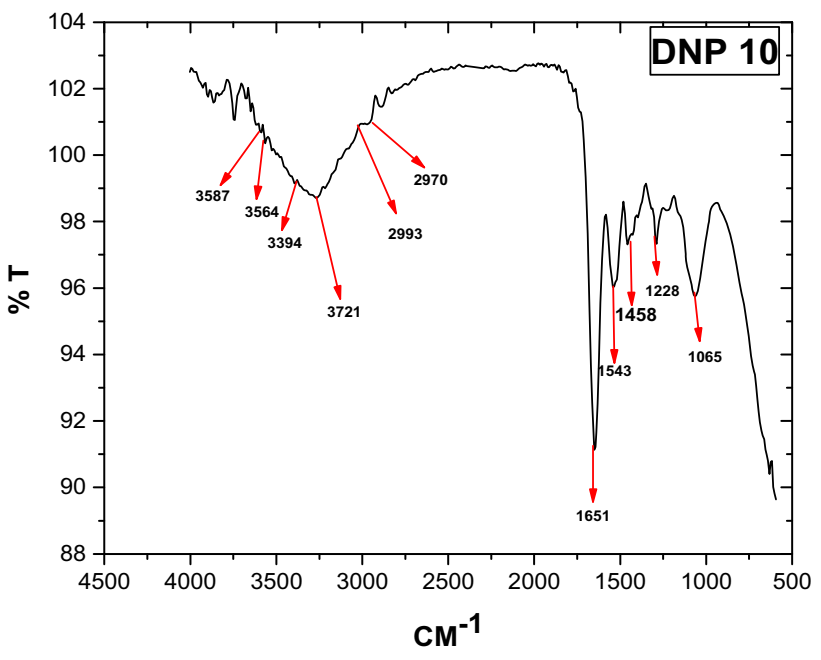

Fig. 5 FTIR analysis of biologically synthesized silver nanoparticles

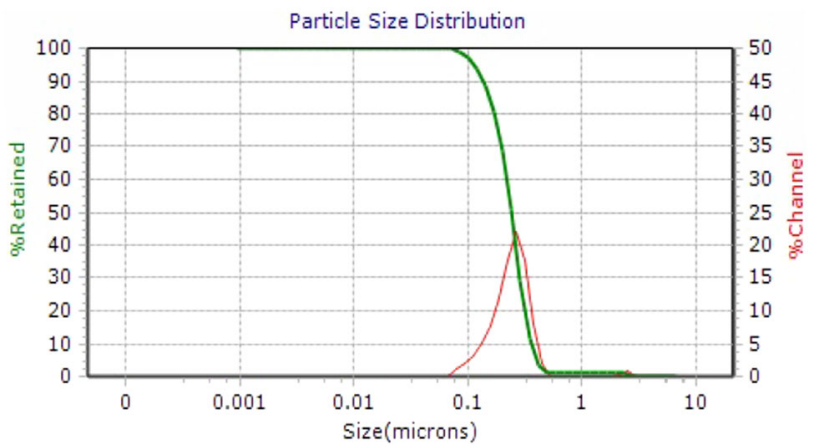

Fig. 6 DLS Analysis of biologically synthesized silver nanoparticles

against all tested pathogens as shown in Fig. 7. The highest antimicrobial activity of silver nanoparticles synthesized by $L$. varians was found against $C$. albicans $(23 \mathrm{~mm})$ and C. glabrata $(21.33 \mathrm{~mm})$. The lowest antimicrobial activity of biologically synthesized silver nanoparticles was found against $F$. graminearum $(14 \mathrm{~mm})$ as shown in Fig. 8 . However, antimicrobial activity of silver nanoparticles was significantly higher than silver nitrate in case of E. coli and P. fluorescens. The MIC values of AgNPs for the selected strains were calculated and summarized in Table 2. The MIC of silver nanoparticles was observed as $46 \mu \mathrm{g}$ for E. coli, P. aeruginosa, Bacillus subtilis, S. aureus and $23 \mu \mathrm{g}$ for C. albicans.

\section{Discussion}

The bacterial mediated synthesis of silver nanoparticles is an attractive and alternative to chemically and physically produced AgNPs due to their green properties. The biological methods of nanoparticle synthesis are economical, 
Fig. 7 Antimicrobial activity of biologically synthesized AgNP against pathogenic microorganisms a Bacillus subtilis, b Escherichia coli, c Pseudomonas aeruginosa, d Streptococcus mutans, e Pseudomonas fluorescens, f Candida albicans, g Streptococcus pyogenes, h Staphylococcus aureus, i Fusarium graminearum, and j Candida glabrata

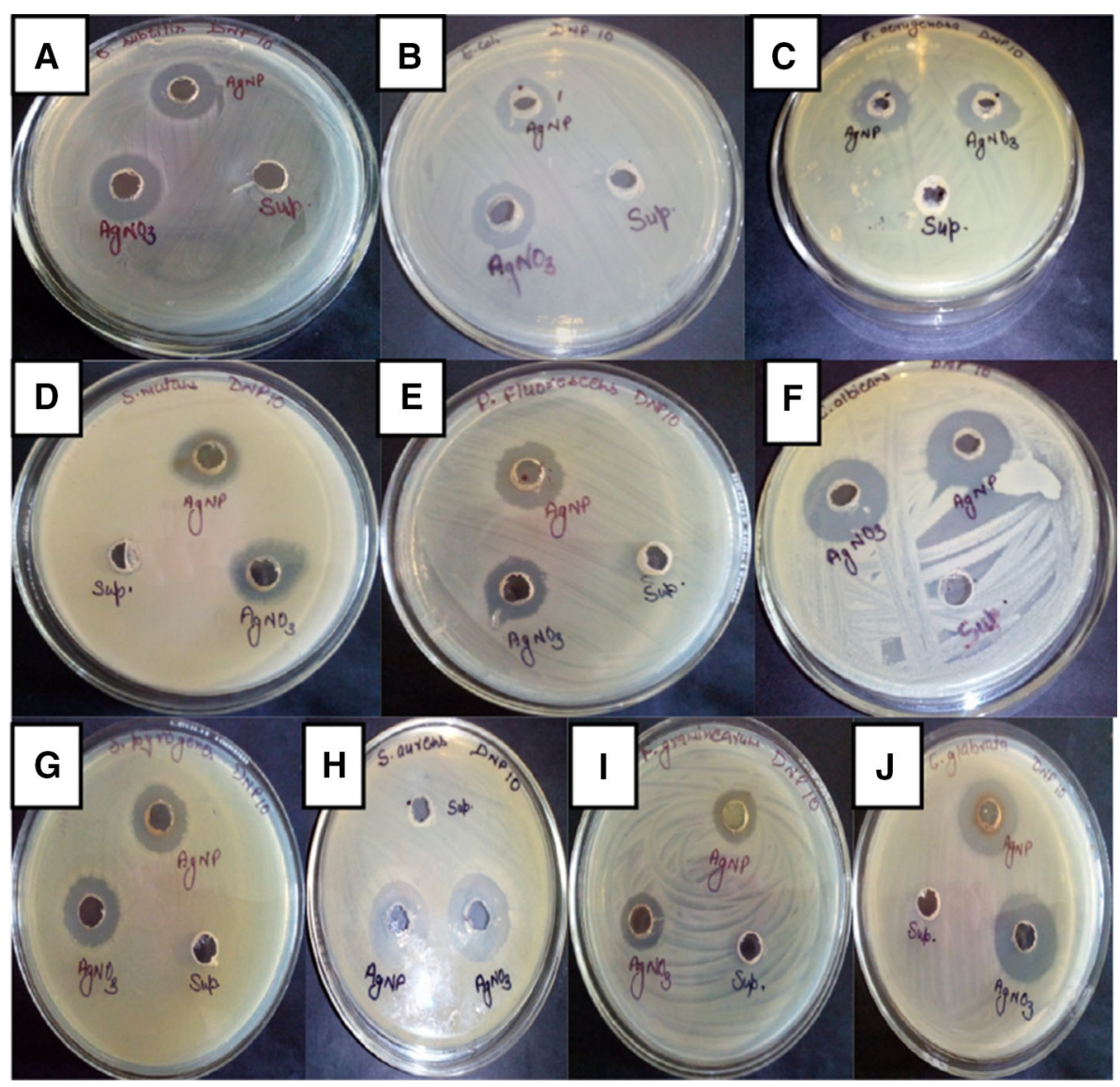

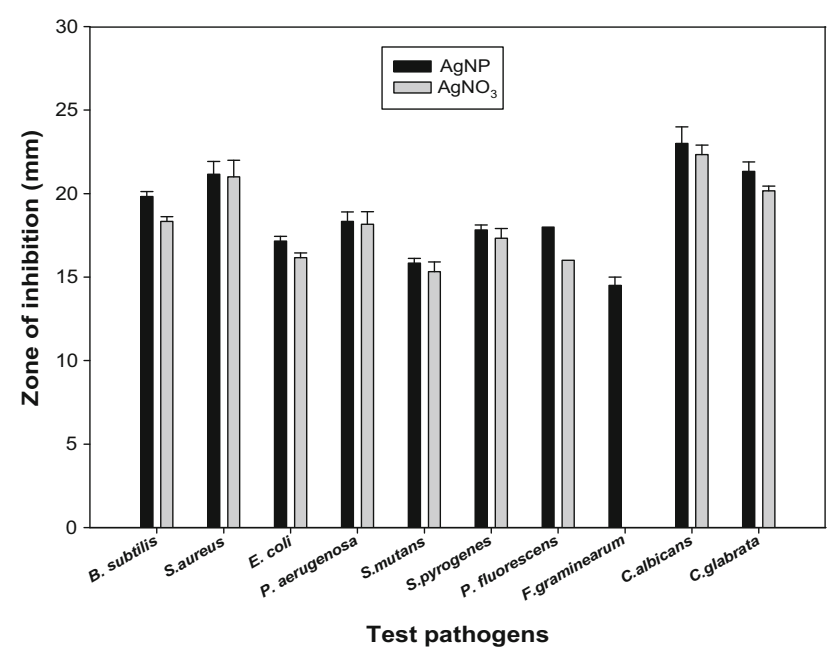

Fig. 8 Antimicrobial activity of silver nanoparticles (in $\mathrm{mm}$ )

easy to perform and environment friendly. Silver nanoparticle had drawn attention because of their extensive application to new technologies in chemistry, electronics, medicine and biotechnology. In the present study, the selected bacterial strain DNP 10 identified as L. varians showed ability to synthesize silver nanoparticles by extracellular mechanisms. The screening of microbial isolate for silver nanoparticle synthesis is generally carried out on the basis of colour change (Kalimuthu et al. 2008). Appearance of a dark-brown colour in the solution is a primary indication for AgNPs formation in the reaction mixture (Sastry et al. 2003). The excitation of surface plasmon vibration in silver nanoparticles was considered as the basis for formation of brown colour. Similar observation was previously reported in various studies, where a pale yellow to brown colour was formed due to the reduction of aqueous silver ions to silver nanoparticles (Saravanan et al. 2011). Silver nanoparticles synthesis has also been reported by using Lysinibacillus sphaericus MR-1 (Gou et al. 2015) and Lysinibacillus fusiformis (Yousef 2014). The extracellular synthesis of silver nanoparticles by using culture supernatant of various bacteria B. licheniformis (Kalishwaralal et al. 2008), Pseudomonas aeruginosa (Jeevan et al. 2012), Lactobacillus sp. (Ranganath et al. 2012), Exiguobacterium sp. KNU1 (Dhawal and Dae 2013) and probiotic bacteria B. Linens (Ranganathan and Ramachandran 2012) has already been reported. This supports that colour change can be considered as an indication of silver nanoparticles formation. The synthesis process adopted in this study was much faster than previously reported bioreduction processes, which requires hours or days (Vivekanandhan et al. 2014; Song et al. 2009). Synthesis of 
Table 2 MIC of silver nanoparticles by agar well diffusion assay

\begin{tabular}{|c|c|c|c|c|c|}
\hline \multicolumn{6}{|c|}{ Zone of inhibition $(\mathrm{mm})$} \\
\hline \multirow{2}{*}{ Test pathogen } & \multicolumn{5}{|c|}{ Silver nanoparticles concentration (in $\mu \mathrm{g}$ ) } \\
\hline & 375 & 187.5 & 93.7 & 46.85 & 23.42 \\
\hline B. subtilis & 20 & 19 & 18 & 15 & 0 \\
\hline S. aureus & 21 & 20 & 19 & 14 & 0 \\
\hline E. coli & 19 & 18 & 17 & 14 & 0 \\
\hline P. aeruginosa & 18 & 16 & 15 & 12 & 0 \\
\hline C. albicans & 23 & 21.5 & 20 & 19 & 15 \\
\hline
\end{tabular}

silver nanoparticles was further confirmed by UV-Vis spectroscopy, which measures the absorption spectra of silver nanoparticles formed due to collective excitation of conduction electrons in the metal. Thus, methods based on UV-Vis spectroscopy have been shown to be an effective technique for the analysis of nanoparticles (Sastry et al. 1998). This is already reported that spherical silver nanoparticles exhibit maximum absorbance between 420 and $450 \mathrm{~nm}$ (Ninganagouda et al. 2013; Sunkar and Nachiyar 2012). The size, shape, morphology, composition and dielectric environment of prepared nanoparticles affect the width of SPR bands (Kelly et al. 2003).

The XRD spectrum of synthesized nanoparticles was in agreement with diffraction standard JCPDS 04-0783, which confirms the presence of elemental silver. The XRD peaks at $2 \theta$ of $38.07,46.24,54.82$ and 77.110 could be attributed to $111,200,220$ and 311 crystallographic planes of face-centered cubic silver crystals, respectively. Thus, XRD pattern clearly confirms the crystalline nature of AgNPs synthesized in this study. As per XRD analysis in the absence of PVP, silver oxide nanoparticles were formed instead of silver nanoparticles. The PVP was added to stabilize the formation of silver nanoparticles. So, it can be inferred that the extracellular protein present in culture supernatant were responsible for the reduction of silver nitrate and PVP played a major role in the stabilization of formed silver nanoparticles.

TEM analysis of purified silver nanoparticles confirmed that nanoparticles were spherical and also not aggregated. Protein secreted by microorganisms may be responsible for the stability of silver nanoparticles. The size of silver nanoparticles produced by $L$. varians $(10-20 \mathrm{~nm})$ fall closer to the size of silver nanoparticles produced by other bacteria (Gurunathan et al. 2009). The silver nanoparticles produced extracellularly by using probiotic bacteria Lactobacillus sp. were also in size range of 2-20 nm (Ranganath et al. 2012). The size of nanoparticles can have direct effect on its physico-chemical properties and this can vary among the particles formed by different groups of microorganisms.
The peaks observed at wave number $1651 \mathrm{~cm}^{-1}$ indicated the stretching of $\mathrm{C}=\mathrm{O}$ amide $\mathrm{I}$ bands of peptide linkage and $1288 \mathrm{~cm}^{-1}$ indicated stretching of $\mathrm{CN}$ amines and $\mathrm{NH}$ bending of peptide. The peak at $1057 \mathrm{~cm}^{-1}$ was due to stretching of $\mathrm{C}-\mathrm{OH}$ in primary alcohols. This is reported that the carbonyl group $(\mathrm{C}=\mathrm{O})$ of amino acid residues and peptides has the ability to bind silver ion (Balaji et al. 2009). The FTIR spectrum indicated that proteins were responsible for stabilizing the silver nanoparticles. DLS measures the hydrodynamic size of silver nanoparticles. The size measured by DLS is not only the size of metallic nanoparticles but it also includes the stabilizers absorbed on the surface of nanoparticles. Thus the size measured by DLS is larger than measured by other techniques. The particles carry a charge of $-44.55 \mathrm{mV}$. This confirms that the biologically synthesized silver nanoparticles are stable. A minimum of $\pm 30 \mathrm{mV}$ is an indication of stability of silver nanoparticles (Jacobs and Muller 2002). The polydispersity index (PdI) of silver nanoparticles was below 0.3 .

The antimicrobial activity of silver nanoparticles has been reported against fungus, yeast, microbial biofilms yeast, Gram-negative and Gram-positive bacteria (Kim et al. 2007; Sondi and Salopek-Sondi 2004; Abdeen et al. 2014; Gaidhani et al. 2013; Singh et al. 2013). Antimicrobial activity of silver nanoparticles has been reported against both Grampositive as well as Gram-negative bacteria (Sondi and Salopek-Sondi 2004). The antimicrobial activity of synthesized nanoparticles was reported against $P$. aeruginosa, $S$. aureus, Aspergillus flavus and Aspergillus niger (Govindaraju et al. 2010; Mirzajani et al. 2011). AgNPs synthesized by isolated bacterial strain DNP 10 (L. varians) showed excellent antibacterial activity against all tested strains (bacterial and fingal). In this study, MIC of PVP coated silver nanoparticles against E. coli, S. aureus, B. subtilis, P. aeruginosa was evaluated as $46 \mu \mathrm{g} / \mathrm{mL}$.MIC of silver nanoparticles against C. albicans was evaluated as $23 \mu \mathrm{g} / \mathrm{mL}$. Various studies have reported different values of MIC for different pathogens. Shrivastava et al. (2009) determined the average MIC value of AgNPs against E. coli as 25 and $100 \mu \mathrm{g} / \mathrm{mL}$ MIC value against $S$. aureus. However, Dos Santos et al. (2014) 
reported MIC value as $100 \mu \mathrm{g} / \mathrm{mL}$ for both $E$. coli and $S$. aureus. MIC of silver nanoparticles against $P$. aeruginosa has been reported as $75 \mu \mathrm{g} / \mathrm{mL}$ (Morones et al. 2005) and $20 \mu \mathrm{g} / \mathrm{mL}$ (Palanisamy et al. 2014) in two different studies. MIC of silver nanoparticles against $B$. subtilis is reported as $40 \mu \mathrm{g} / \mathrm{mL}$ (Ruparelia et al. 2008). Different MIC values for same pathogens may be due to difference in strains of pathogens, source of pathogens and different size and shape of nanoparticles. Stabilization method employed for synthesized nanoparticles also influenced the efficiency of silver nanoparticles. MIC of citrate capped silver nanoparticles has been reported as $5-10 \mu \mathrm{g} / \mathrm{mL}$ against $E$. coli (Zhou et al. 2012). Polyvinylpyrrolidone (PVP) showed good antibacterial activity towards $S$. aureus, E. coli, P. aeruginosa, Bacillus subtilis and good fungicidal activity against various yeasts and molds (Bryaskova et al. 2011). The antimicrobial activity of AgNPs is inversely related to size and shape (Pal et al. 2007). The high specific surface-to-volume ratio of silver nanoparticles increases their contact with microorganisms, promoting the dissolution of silver ions, thereby improving biocidal effectiveness. The ability of silver nanoparticles to release silver ions is a key to their bactericidal activity (Stobie et al. 2008).

\section{Conclusion}

In conclusion, $L$. varians possess an ability to synthesize silver nanoparticles by extracellular method. The process adopted for nanoparticles synthesis was simple, fast, environment friendly and easy to perform. The biologically synthesized PVP coated silver nanoparticles were stable and well dispersed. The synthesized silver nanoparticles showed antimicrobial activity against bacteria, fungi and plant pathogen. This study showed that biologically synthesized Ag-NPs have great potential of antimicrobial agent and can have application in various fields.

Acknowledgments The work was financially supported under the scheme of UGC JRF (Ref No. 22/12/2013(ii) EU-V) by University Grant Commission New Delhi, India to the first author. We thank the sophisticated analytical instrument facility (SAIF), Panjab University, Chandigarh for accessing TEM facility.

\section{Compliance with ethical standards}

\section{Conflict of interest None.}

Open Access This article is distributed under the terms of the Creative Commons Attribution 4.0 International License (http:// creativecommons.org/licenses/by/4.0/), which permits unrestricted use, distribution, and reproduction in any medium, provided you give appropriate credit to the original author(s) and the source, provide a link to the Creative Commons license, and indicate if changes were made.

\section{References}

Abdeen S, Geo S, Sukanya Praseetha PK, Dhanya RP (2014) Biosynthesis of silver nanoparticles from Actinomycetes for therapeutic applications. Int J Nano Dimens 5:155-162

Ahmad R, Minaeian S, Shahverdi HR, Jamalifar H, Nohi A (2007) Rapid synthesis of silver nanoparticles using culture supernatants of Enterobacteria: a novel biological approach. Process Biochem 42:919-923

Baker S, Shreedharmurthy S (2012) Antimicrobial activity and biosynthesis of nanoparticles by endophytic bacterium inhabiting Coffee arabica L. Sci J Biol Sci 1(5):107-113

Balaji D, Basavaraja S, Deshpande S, Bedre R, Mahesh D, Prabhakar BK et al (2009) Extracellular biosynthesis of functionalized silver nanoparticles by strains of Cladosporium cladosporioides. Colloids Surf B Biointerfaces 68:88-92

Bosetti M, Masse A, Tobin E, Cannas M (2002) Silver coated materials for external fixation devices: in vitro biocompatibility and genotoxicity. Biomater 23(3):887-892

Bryaskova R, Pencheva D, Nikolov S, Kantardjiev T (2011) Synthesis and comparative study on the antimicrobial activity of hybrid materials based on silver nanoparticles (AgNPs) stabilized by polyvinylpyrrolidone (PVP). J Chem Biol 4(4):185-191

Chen MS, Goodman DW (2004) The structure of catalytically active $\mathrm{Au}$ on titania. Science 306:252-255

Cho Chung H, Choi W, Yoon J (2005) Different inactivation behaviors of MS-2 phage and Escherichia coli in $\mathrm{TiO}_{2}$ photocatalytic disinfection. Appl Environ Microbiol 71(1):270g

Dhawal PT, Dae SL (2013) Mechanistic antimicrobial approach of extracellularly synthesized silver nanoparticles against gram positive and gram negative bacteria. J Hazard Mater 260:878-884

Dos Santos CA, Seckler MM, Ingle AP, Gupta I, Galdiero S, Galdiero M, Gade A, Rai M (2014) Silver nanoparticles: therapeutical uses, toxicity and safety issues. J Pharm Sci 103:1931-1944

Duran N, Priscyla D, Marcato PD, Alves O, De Souza G, Esposito E (2005) Mechanistic aspects of biosynthesis of silver nanoparticles by several Fusarium oxysporum strains. J Nanobiotechnol $3: 1-7$

Gaidhani S, Singh R, Singh D, Patel U, Shevade K, Yeshvekar R, Chopade BA (2013) Biofilm disruption activity of silver nanoparticles synthesized by Acinetobacter calcoaceticus PUCM 1005. Mater Lett 108:324-327

Gou Y, Zhou R, Ye X, Gao S, Li X (2015) Highly efficient in vitro biosynthesis of silver nanoparticles using Lysinibacillus sphaericus MR-1 and their characterization. Sci Technol Adv Mater 16:1-8

Govindaraju K, Tamilselvan S, Kiruthiga V, Singaravelu G (2010) Biogenic silver nanoparticles by Solanum torvum and their promising antimicrobial activity. J Biopest 3:394-399

Gupta A, Silver S (1998) Molecular Genetics: silver as a biocide: will resistance become a problem. Nat Biotechnol 16:888

Gurunathan S, Kalishwaralal K, Vaidyanathan R, Deepak V, Pandian SRK, Muniyandi J, Hariharan N, Eom SH (2009) Biosynthesis, purification and characterization of silver nanoparticles using Escherichia coli. Colloids Surf B Biointerfaces 74:328-335

Hubenthal F, Hendrich C, Ouacha H, Blazquez Sanchez D, Trager F (2005) Preparation of gold nanoparticles with narrow size distributions and well defined shapes. Int J Modern Phys B 19:2604

Jacobs C, Muller RH (2002) Production and characterization of a budesonide nanosuspension for pulmonary administration. Pharmaceut Res 19:189-194 
Jain P, Pradeep T (2005) Potential of silver nanoparticle-coated polyurethane foam as an antibacterial water filter. Biotechnol Bioeng 90(1):59-63

Jain PK, Lee KS, El-Sayed IH, El-Sayed MA (2006) Calculated absorption and scattering properties of gold nanoparticles of different size, shape, and composition: applications in biological imaging and biomedicine. J Phys Chem 110:7238-7248

Jain N, Bhargava A, Majumdar S, Tarafdar JC, Panwar J (2011) Extracellular biosynthesis and characterization of silver nanoparticles using Aspergillus flavus NJP08: a mechanism perspective. Nanoscale 3:635-641

Jeevan P, Ramya K, Rena AE (2012) Extracellular biosynthesis of silver nanoparticles by culture supernatant of Pseudomonas aeruginosa. IJBT 11:72-76

Kalimuthu K, Babu RS, Venkataraman D, Bilal M, Gurunathan S (2008) Biosynthesis of silver nanocrystals byBacillus licheniformis. Coll Surf B 65:150-153

Kalishwaralal K, Deepak V, Ramkumarpandian S, Nellaiah H, Sangiliyandi G (2008) Extracellular biosynthesis of silver nanoparticles by the culture supernatant of Bacillus licheniformis. Mater Lett 62:4411-4413

Kalishwaralal K, Deepak V, Pandian SRK, Kottaisamy M, Barath ManiKanth S, Kartikeyan B, Gurunathan S (2010) Biosynthesis of silver and gold nanoparticles using Brevibacterium casei. Coll Surf B 77:257-262

Kelly KL, Coronado E, Zhao LL, Schatz GC (2003) The optical properties of metal nanoparticles: the influence of size, shape and dielectric environment. J Phys Chem 107:668-677

Kim JS, Kuk E, Yu KN, Kim JH, Park SJ, Lee HJ, Kim SH, Park YK, Park YH, Hwang CY et al (2007) Antimicrobial effects of silver nanoparticles. Nanomedicine 3:95-101

Li Q, Mahendra S, Lyon DY, Brunet L, Liga MV, Li D, Alvarez P (2008) Antimicrobial nanomaterials for water disinfection and microbial control: potential applications and implications. Water Res 42:4591-4602

Liu J, Qiao SZ, Hu QH (2011) Magnetic nanocomposites with mesoporous structures: synthesis and applications. Small $7: 425-443$

Mirzajani F, Ghassempour A, Aliahmadi A, Esmaeili MA (2011) Antibacterial effect of silver nanoparticles on Staphylococcus aureus. Res Microbiol 162:542-549

Mohanpuria P, Rana NK, Yadav SK (2008) Biosynthesis of nanoparticles: technological concepts and future applications. J Nanopart Res 7:9275-9280

Morones JR, Elechiguerra JL, Camacho A, Holt K, Kouri JB, Ramírez JT, Yacaman MJ (2005) The bactericidal effect of silver nanoparticles. Nanotechnol 16(10):2346-2353

Ninganagouda S, Rathod V, Jyoti H, Singh D, Prema K, Manzoor-UlHaq (2013) Extracellular biosynthesis of silver nanoparticles using Aspergillus flavus and their antimicrobial activity against gram negative MDR strains. Int J Pharm Bio Sci 4(2):222-229

Pal S, Tak YK, Song JM (2007) Does the antibacterial activity of silver nanoparticles depend on the shape of the nanoparticle A study of the gram-negative bacterium Escherichia coli. Appl Environ Microbiol 73:1712-1720

Palanisamy NK, Ferina N, Amirulhusni AN, Zain ZM, Hussaini J, Liew Ping LJ, Durairaj R (2014) Antibiofilm properties of chemically synthesized silver nanoparticles found against Pseudomonas aeruginosa. J Nanobiotechnol 12:2

Perez C, Paul M, Bazerque P (1990) Antibiotic assay by agar well diffusion method. Acta Biol Med Exp 15:113-115
Pugazhenthiran N, Anandan S, Kathiravan G, Prakash NKU, Crawford S, Ashok kumar M (2009) Microbial synthesis of silver nanoparticles by Bacillus sp. J Nanopart Res 11:1811-1815

Rai M, Yadav A, Gade A (2009) Silver nanoparticles as a new generation of antimicrobials. Biotechnol Adv 27:76-83

Ranganath E, Rathod V, Banu A (2012) Screening of Lactobacillus sp. for mediating the biosynthesis of silver nanoparticles from silver nitrate. IOSR PHR 2(2):237-241

Ranganathan N, Ramachandran R (2012) Synthesis of silver nanoparticles using a probiotic microbe and its antibacterial effect against multidrug resistant bacteria. Afr J Biotechnol 11(49):11013-11021

Ruparelia JP, Chatterjee AK, Duttagupta SP, Mukherji S (2008) Strain specificity in antimicrobial activity of silver and copper nanoparticles. Acta Biomater 4:707-716

Saifuddin N, Wong CW, NurYasumira AA (2009) Rapid biosynthesis of silver nanoparticles using culture supernatant of bacteria with microwave irradiation. J Chem 6:61-70

Saravanan M, Vemu AK, Barik SK (2011) Rapid biosynthesis of silver nanoparticles from Bacillus megaterium (NCIM 2326) and their antibacterial activity on multi drug resistant clinical pathogens. Coll Surf B 88:325-331

Sastry M, Patil V, Sainkar SR (1998) Electrostatically controlled diffusion of caroboxylic acid derivatized silver colloidal particles in thermally evaporated fatty amine films. J Phys Chem B 102:1404-1410

Sastry M, Ahmad A, Khan MI, Kumar R (2003) Biosynthesis of metal nanoparticles using fungi and actinomycete. Curr Sci 85:162-170

Shrivastava S, Bera T, Singh SK, Singh G, Ramachandrarao P, Dash D (2009) Characterization of antiplatelet properties of silver nanoparticles. ACS Nano 3:1357-1364

Singh R, Wagh P, Wadhwani S, Gaidhani S, Kumbhar A, Bellare J, Chopade BA (2013) Synthesis, optimization, and characterization of silver nanoparticles from Acinetobacter calcoaceticus and their enhanced antibacterial activity when combined with antibiotics. Int J Nanomedicine 8:4277-4290

Sondi I, Salopek-Sondi B (2004) Silver nanoparticles as antimicrobial agent: a case study on E. coli as a model for Gram-negative bacteria. J Colloid Interface Sci 275:177-182

Song KC, Lee SM, Park TS, Lee BS (2009) Preparation of colloidal silver nanoparticles by chemical reduction method. Korean $\mathrm{J}$ Chem Eng 26:153-1555

Stobie N, Duffy B, McCormack DE, Colreavy J, Hidalgo M, McHale P, Hinder SJ (2008) Prevention of Staphylococcus epidermidis biofilm formation using a low-temperature processed silver-doped phenyltriethoxysilane sol-gel coating. Biomaterials 29:963-969

Sunkar S, Nachiyar CV (2012) Biogenesis of antibacterial silver nanoparticles using the endophytic bacterium Bacillus cereus isolated from Garcinia xanthochymus. Asian Pac J Trop Biomed 2(12):953-959

Vivekanandhan S, Schreiber M, Mason C, Mohanty AK, Misra M (2014) Maple leaf Acer sp. extract mediated green process for the functionalization of $\mathrm{ZnO}$ powders with silver nanoparticles. Colloid Surface B 113:169-175

Yousef NMH (2014) Characterization and antimicrobial activity of silver nanoparticles synthesized by rice straw utilizing bacterium (Lysinibacillus fusiformis). IJDR 4(9):1875-1879

Zhou Y, Kong Y, Kundu S, Cirillo JD, Liang H (2012) Antibacterial activities of gold and silver nanoparticles against Escherichia coli and Bacillus Calmette-Guerin. J Nanobiotechnol 10:19 